\title{
Buyanhulu Mine (Tanzania) Paste Tailings Facility: Relating Physical and Geochemical Properties of Gold Tailings to Rate of Rise
}

\author{
J.A. Wates, P. Rousseau Golder Associates Africa (Pty) Ltd, South Africa \\ J. Shuttleworth Bulyanhulu Gold Mine, Tanzania
}

\section{INTRODUCTION}

Bulyanhulu Mine in Tanzania is an underground gold mine, located in a semi-arid climatic region where the net evaporation rate exceeds the rate of precipitation. In these regions, the unsaturated pore spaces in tailings, exist under suction pressures, which play an important part in determining engineering behaviour. Slow rates of deposition and consolidation are important in order to achieve the necessary shear strength and volumetric stability.

The potential for Acid Rock Drainage (ARD) is also influenced by the geotechnical properties as pore water saturation and primary and secondary (crack) porosity are all important influences on the rate that oxygen can be transported to sulphide minerals, which are the cause of ARD.

Geotechnical and geochemical properties were investigated in a $0.6 \mathrm{~m}$ layer of tailings. Drying tests were also done in three cylinders. Geochemical reactions were investigated through sulphur speciation tests and modelling with the PYROX sulphide oxidation model.

Geotechnical observations made during the testing programme were reported by Theron, Addis, Wates and Martin as follows:

- The gradient of the relationship between shrinkage and moisture content is not constant and reflects the expected reduction in shrinkage with decreasing moisture content.

- The rate of increase in dry density decreased over time, which reflects the expected reduction in shrinkage with decreasing moisture content.

- Distance from the discharge point had no significant influence on the gravimetric moisture content of the tailings. The average moisture content decreased over time at a progressively slower rate.

Precipitation was not noted to have any impact on surface moisture content. Surface layers were 
found to dry more quickly than deeper layers, although the difference became less significant over time.

- Suction pressures were noted to increase over time as the tailings dried. Large variations in measured suction pressures are attributed to difficulties with saturating the suction probe for collection of measurements.

- Undrained shear strength increased with time and with distance from the discharge point. The reason for the increasing undrained shear strength with distance from the discharge point is unclear and is inconsistent with the observation that drying rate is not a function of the distance from the discharge point.

The following conclusions were reported by Theron et al.:

- Field measurements were compared with cylinder measurements and it was concluded that boundary conditions differed significantly, thus resulting in significantly different drying rates for the two scenarios. It should however be noted that moisture contents were measured for the cylinders for the total mass of the sample whilst only the top layer of the beach was sampled in-situ.

- Gravimetric moisture content decreased with time whilst volumetric content remained the same over time. Comparison with undrained shear strength and suction data indicates that the volumetric moisture content measured was likely to have been erroneous.

- Soil moisture characteristic curves were obtained using the average volumetric moisture content vs. suction pressures.

- Allowable rate of rise can be calculated by determining the time for a layer of tailings to reach a moisture content at which shrinkage ceases. Maximum allowable rate of rise on this basis would be between 3.6 and $5.2 \mathrm{~m}$ per annum for a layer thickness between 0.6 and $0.3 \mathrm{~m}$. An optimum value was obtained for the $0.6 \mathrm{~m}$ layer thickness $(5.2 \mathrm{~m} / \mathrm{a})$.

This paper reports on further work undertaken during the course of the same testing programme reported on by Theron et al. and extends the analysis and findings of the geotechnical work to include geochemical considerations. The following geochemical conclusions have been drawn from the tests:

- The effect of oxygen diffusion will be limited until the shrinkage limit is reached. This is because void saturation remains high and constant until this point and gas diffusion occurs almost exclusively through unsaturated pore space. Sulphide oxidation is thus likely to be inhibited until the shrinkage limit is reached. 
- Cracking has a significant impact on the area available for oxygen ingress and hence on the oxidation rate. The crack patterns and the time at which cracking occurs would thus have a significant effect on the time delay before onset of an accelerated oxidation phase for different layer thicknesses.

- According to the PYROX model, oxidation will only occur in the top $5 \mathrm{~cm}$ of the tailings profile in the first three months after deposition, thus indicating shallow penetration at exposed surfaces.

- Expected oxidation rates were calculated for different rates of rise. It was found that a thicker tailings beach is optimal, as the average rate of sulphide oxidation is lower over the life of the tailings facility, despite the longer depositional interval. This trend must be confirmed for field conditions, however, as the conclusions are based on the cylinder tests.

- Sulphur speciation analyses indicated that sulphide oxidation will contribute approximately $5 \%$ to $15 \%$ of the total oxidised sulphur (sulphate) in the upper layer over a period of 30 days after deposition for the Bulyanhulu tailings.

- Calculated oxidation rates agree well with measured rates, over a $20 \mathrm{~cm}$ profile depth. No significant differentiation with depth was observed, however, thus indicating secondary factors, e.g. biological oxidation and/or reduction of sulphide minerals.

The paper concludes that despite the longer interdepositional periods required to build thicker beaches, thicker beaches will retard the rate of ARD generation.

It thus follows that the optimum depositional cycle is that which reaches the moisture content below which there is no further shrinkage, just in time to receive the next layer.

\section{Discussion}

\section{$2.1 \quad$ Measurements}

Field and laboratory measurements were conducted over a period of 3 months. Multiple measurements were collected across the beach slope on a variable time scale (generally daily, weekly or monthly), depending on the parameter being measured and the period of time that had elapsed. The following parameters were measured:

- Field measurements

○ beach thickness measurements (installation of measuring stakes prior to deposition),

○ crack width and spacing measurements (tape measure), 
○ pore water suction measurements (quick draw tensiometer),

○ undrained shear strength measurements (hand shear vane),

○ tailings temperature (Acorn Temp 4 thermistor probe),

○ bulk density (sand replacement technique),

○ dry density measurements (sand replacement technique),

○ volumetric moisture content (soil moisture theta probe), and

○ drying rates (300 mm diameter steel cylinders with tailings depths of 150, 300, 600 and 900 $\mathrm{mm}$.

- Laboratory measurements

- gravimetric moisture content (oven drying),

- shrinkage of tailings samples as a function of drying (ruler),

○ sulphur speciation (Methodology of Price 1997),

○ mineralogy (X-ray diffraction (XRD)), and

○ particle size distribution (Sieve and hydrometer particle size analysis).

\subsection{Uncertainties in the analytical results}

- The analytical results obtained were generally used as is, with the exception of volumetric moisture content and cylinder drying rates.

- The measured volumetric moisture content was considered to be unreliable. This is due to the theta probe being sensitive to salinity effects, which are significant in the pore waters of Bulyanhulu paste tailings.

- The cylinder drying rates were found to be higher than expected. This was attributed to differing boundary conditions, relative to the deposited beach.

- Additional complications were introduced through rainfall events, which flooded the sealed cylinders. Due to the sealed containers, excess water needed to be decanted by hand, as they were not free draining. 


\subsection{Geotechnical properties}

From a geotechnical point of view, the maximum rate of rise is governed by the drying time required to reach the shrinkage limit of the material, i.e. a moisture content where shrinkage ceases (Wates et al. 1999).

The determined geotechnical properties were analysed and a number of important findings were made, which have a direct impact on ARD generation rates. Despite a level of uncertainty, specifically due to a lack of sufficient dry density measurements, it was found that there is an apparent relationship between moisture content, cracking, pore water saturation and the shrinkage limit.

Correlation of the shrinkage limit vs. the volumetric moisture content, indicated that shrinkage occurs without a reduction in the level of pore water saturation. Field measurements of volumetric moisture content were considered to be inaccurate due to salinity affecting probe readings, although they agreed relatively well with calculated values, which indicated a constant or increasing level of saturation during consolidation. Calculated values (see equation 1) were used in preference to measured values due to the expected inaccuracies, despite the small number of available dry density measurements.

$$
\theta_{w}=S \omega G_{s} /\left(S+\omega G_{s}\right)
$$

Where, $\theta_{w}=$ Volumetric moisture content, $S=$ Saturation, $\omega=$ Gravimetric moisture content, and $G_{s}=$ Specific Gravity.

The constant pore water saturation level is attributed to the simultaneous reduction in porosity through shrinkage (Figure 1) and loss of water through evaporation (Figure 2). Although Figure 3 indicates an increasing trend in saturation, variability in saturation is considered to be due to analytical error for the purposes of this work, as this is considered the most conservative approach, given the small number of measurements.

Once the shrinkage limit is reached (approximately $20 \%$ gravimetric moisture content in Bulyanhulu tailings), hydrostatic pressure no longer plays a significant role in supporting the material matrix and saturation decreases as a function of evaporation only. At this moisture content, it can also be seen that the rate of moisture loss reduces substantially (see Figure 2).

The potential for cracking to act as a conduit for oxygen ingress was also investigated. Crack spacings were assumed to be approximately double the beach thickness, as this was observed for measured values and has been found at other facilities as well. 


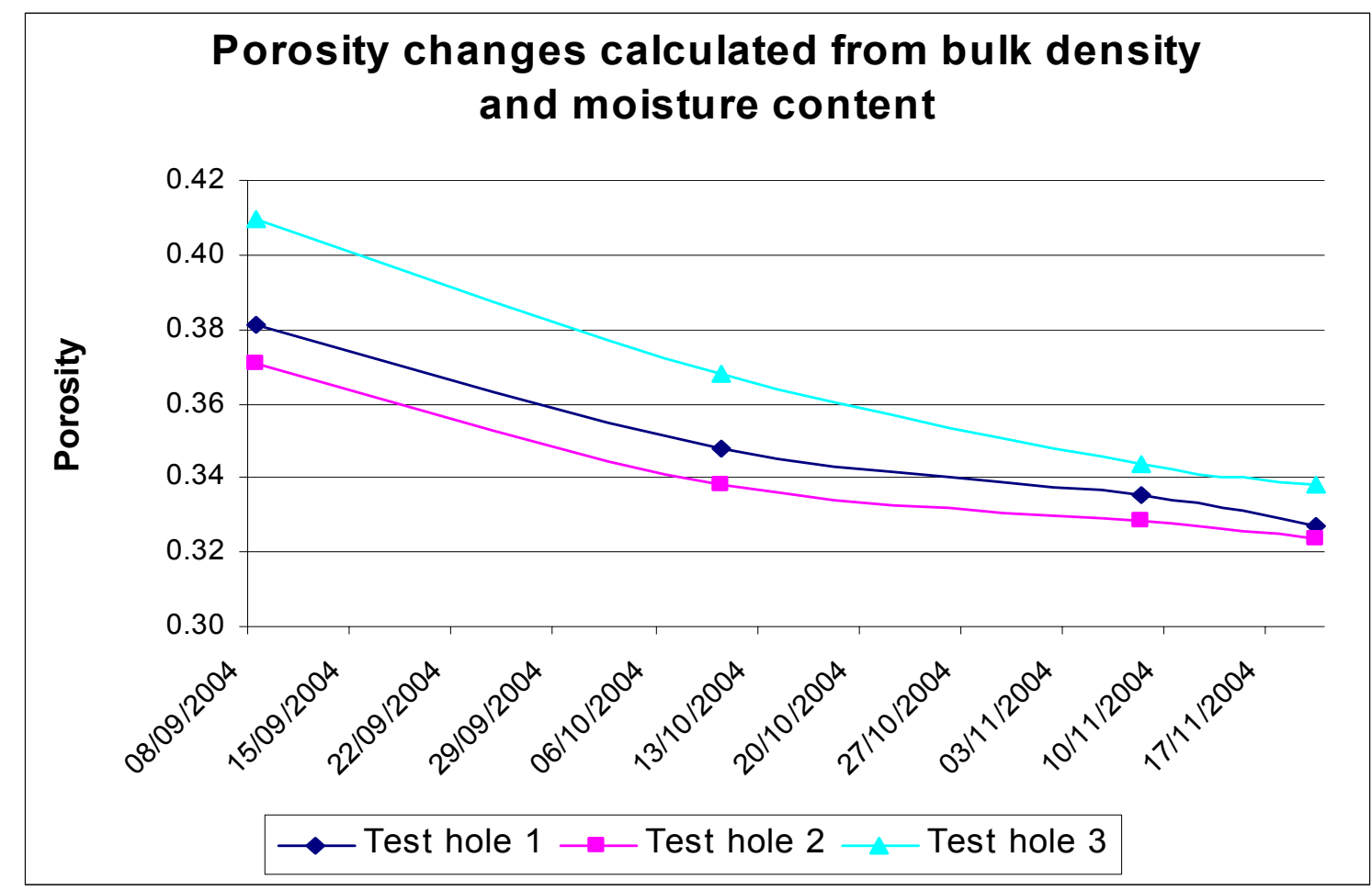

Figure 1 Decrease in porosity

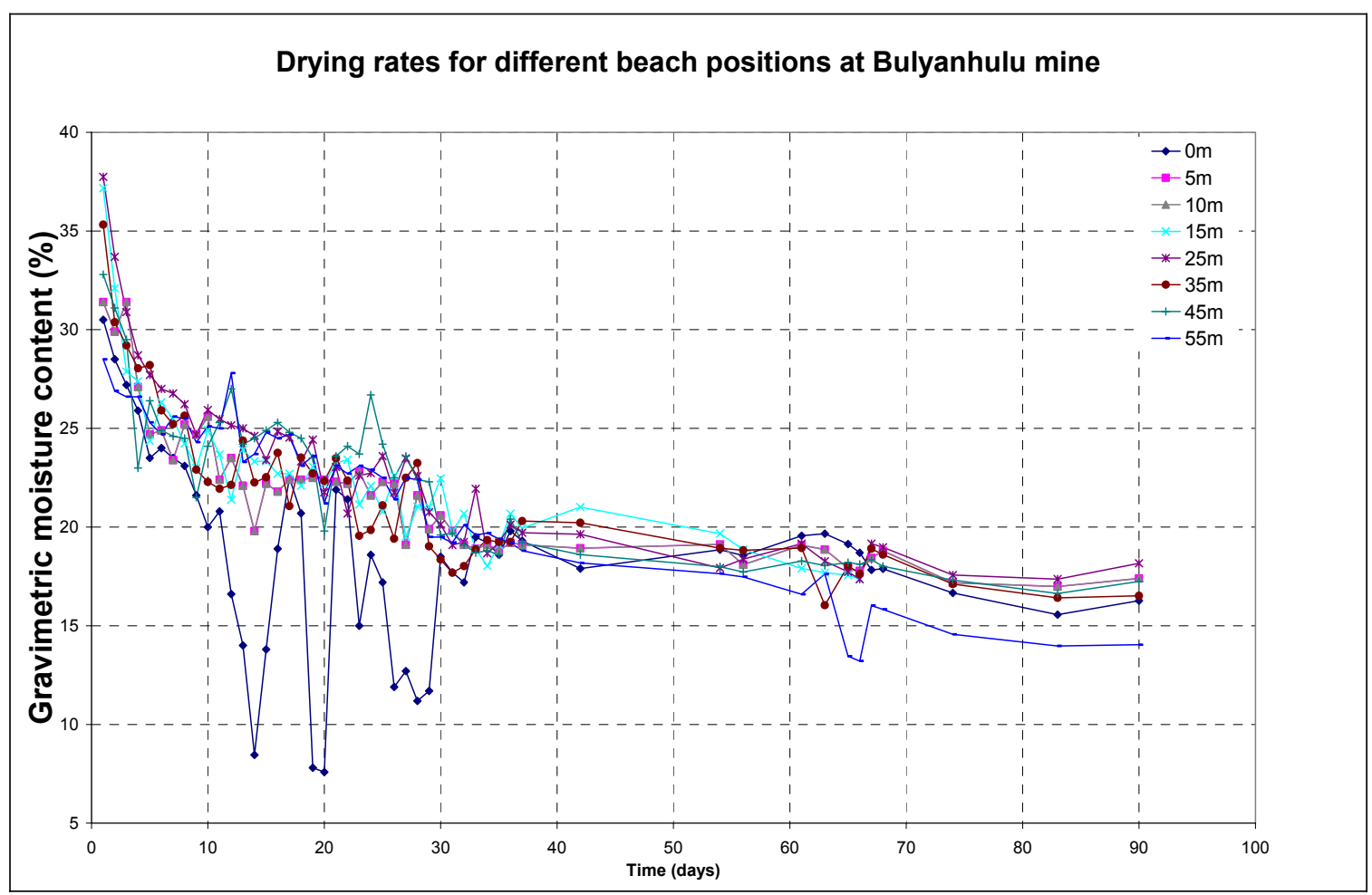

Figure 2 Gravimetric moisture content as a function of time 


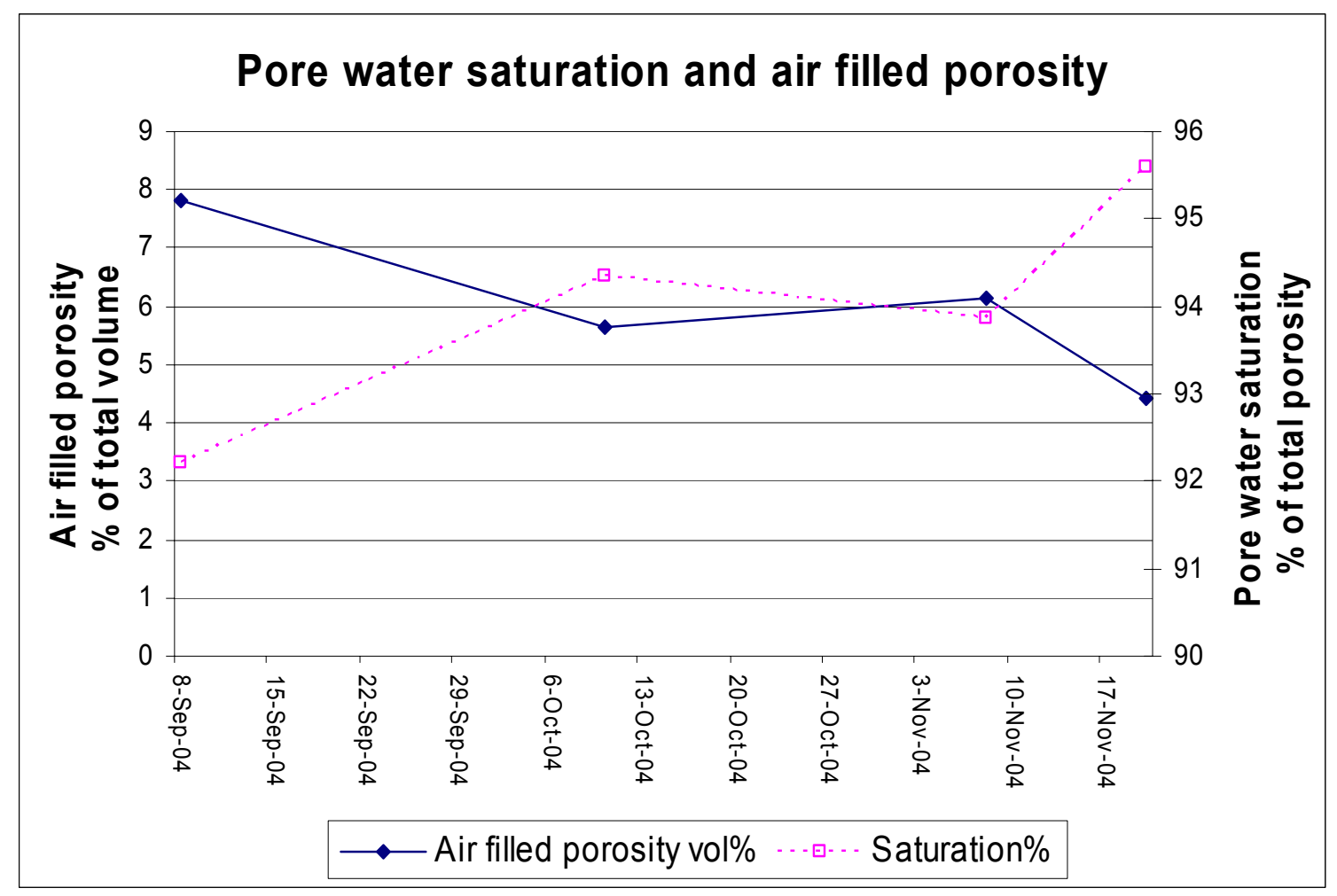

Figure 3 Saturation as a function of drying time

\subsection{Geochemical properties}

The tailings were analysed by XRD for mineralogy. The results are provided in Table 1 .

Table $1 \quad$ Mineralogy of Bulyanhulu tailings

\begin{tabular}{|l|c|}
\hline Mineral & $\mathrm{Wt} \%$ \\
\hline Quartz & 49 \\
Chlorite & 17 \\
Mica & 14 \\
Pyrite & 11 \\
Ankerite & 5 \\
Calcite & 4 \\
\hline
\end{tabular}

Sulphur speciation analyses, according to standard techniques (Price, 1997), were conducted on a number of samples. It was found that sulphur concentrations are in the range between $6.5 \%$ and $7.5 \%$ total sulphur, with approximately $50 \%$ present as sulphide and $50 \%$ as sulphate.

\subsection{Sulphate oxidation modelling}

The mechanisms of sulphide oxidation are complex and are discussed in detail in various publications (Morin \& Hutt 1997, Evangelou 1995, Perkins et al. 1995). The sulphate oxidation modelling was conducted from the point of view of depositing tailings at a maximum rate of rise. This rate is considered to be 
dependent on the shrinkage limit of the tailings, as successive layers can only be deposited once preceding layers stop consolidating (Wates et al., 1999).

For the purposes of scenario modelling, a combination of excel spreadsheet models and the double diffusion (Davis and Ritchie, 1986) PYROX (Wunderly et al., 1996) oxidation model were used.

Models were constructed for three different beach thicknesses, i.e. $300 \mathrm{~mm}, 600 \mathrm{~mm}$ and $900 \mathrm{~mm}$. No model was constructed for the $150 \mathrm{~mm}$ beach due to insufficient data. Corrections were made for cracking and variation in drying characteristics as a function of layer thickness.

The drying characteristics of the cylinder drying tests were calibrated against data obtained from the moisture measurements collected on the $600 \mathrm{~mm}$ beach. Due to the observed inconsistencies between cylinder and field drying rates, cylinder rates were divided by a factor of 3.8 to obtain agreement with field measurements. This would account for anomalous boundary conditions and was considered the best approach for calibrating the field result to calculate the expected rate of rise (see Table 2).

\section{Table 2 Drying times and rates of rise for different beach thicknesses}

\begin{tabular}{|c|c|c|}
\hline Beach depth & $\begin{array}{c}\text { Field drying } \\
\text { time } \\
\text { days }\end{array}$ & Rate of rise \\
$\mathrm{mm}$ & 80 & $\mathrm{~m} / \mathrm{a}$ \\
\hline 900 & 42 & 5.1 \\
600 & 31 & 3.6 \\
300 & \\
\hline
\end{tabular}

Sulphur speciation analyses performed on field samples (taken at depths of 50, 100 and $200 \mathrm{~mm}$ ) indicated that variability was too high to calculate sulphide oxidation rates reliably. Unexpectedly, there was no notable difference in oxidation rate with depth in the top $200 \mathrm{~mm}$ of the profile, possibly due to biological activity. The average rate of pyrite oxidation, calculated from the combined data agreed well with modelled values, however, the high variability suggests that calculated values have low significance with respect to drawing conclusions.

Modelling made use of a combination of PYROX and time series modelling in excel. Drying characteristics and cracking times and patterns were taken into account as significant contributors to ARD generation rates. The model results indicated that a progressive decrease in average oxidation rate will occur as the deposited beach thickness increases, although an optimal rate of rise was calculated for a $0.6 \mathrm{~m}$ beach.

The observations made during the testing programme may be summarised as follows:

- Silicates (quartz, mica and chlorite) make up $80 \%$ of the Bulyanhulu tailings, with pyrite (11\%), calcite (5\%) and ankerite (4\%) making up the remainder. 
- Sulphur speciation analyses indicated that there is a high proportion (approximately $50 \%$ ) of sulphate present in the total sulphur analysis in relatively fresh tailings. Little variation in the ratio of oxidised vs. reduced sulphur was noted at $0,5,10$ and $20 \mathrm{~cm}$ depths of tailings. A slight increase in the percentage of oxidised sulphur was noted after approximately two months of exposure, but with no differentiation according to depth, as would be expected.

- ARD was assumed to be caused by pyrite as the dominant sulphide mineral and oxidation was assumed to occur through diffusion through unsaturated pore space. The PYROX model was used to model this system.

- The $\mathrm{D}_{10}$ particle size was estimated at approximately $10 \mu \mathrm{m}$, according to the particle size distribution curve (see Figure 4). The finest particle size of a tailings has a significant influence on the rate of ARD generation since specific surface area is inversely proportional to particle size.

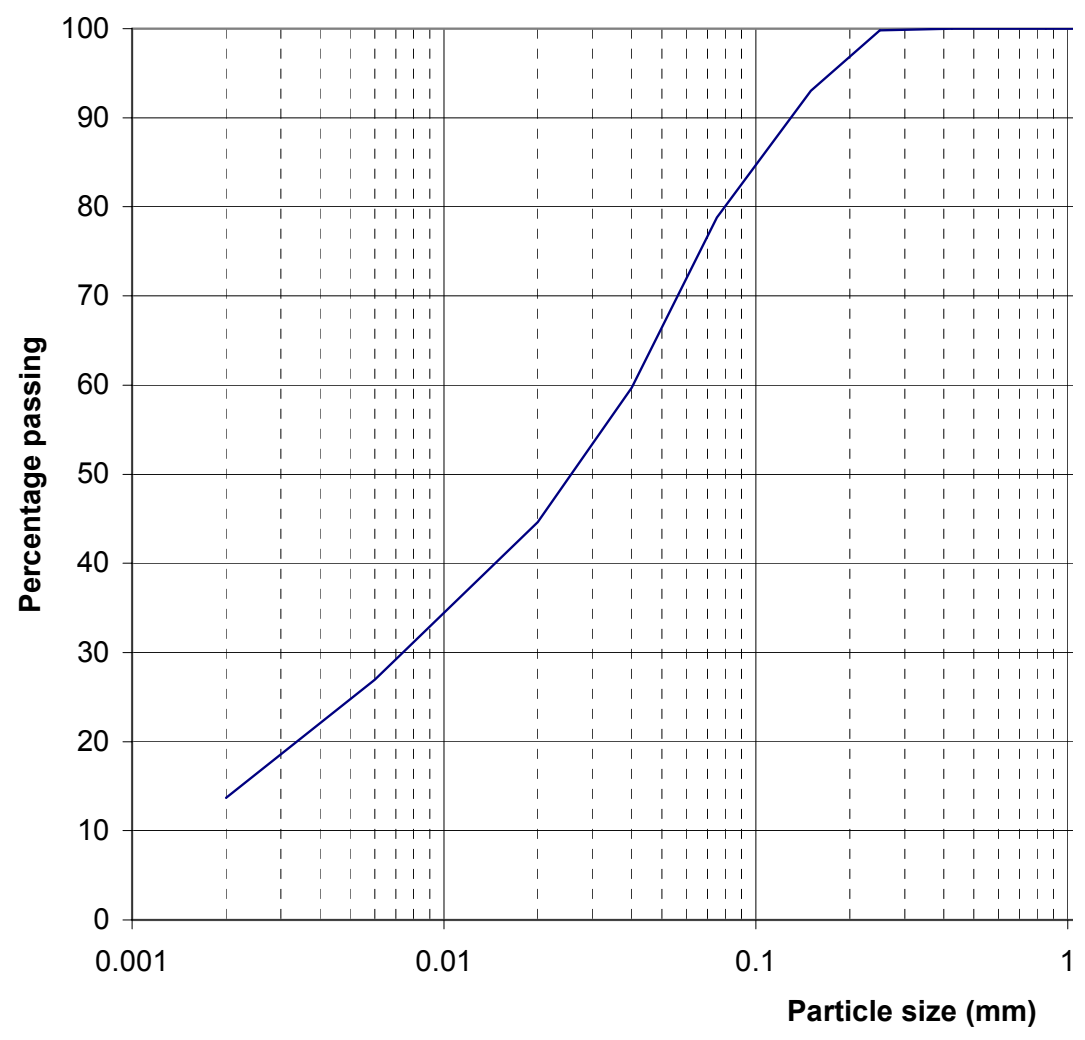

\section{Figure 4 Particle size distribution curve for Bulyanhulu tailings}

- Porosity decreased and density increased as consolidation of the tailings occurred. Pore water saturation was found to remain approximately constant at about $93 \%$ to $94 \%$ until the shrinkage limit was reached. This was attributed to consolidation (decreasing pore space) offsetting evaporation (decreasing water content) to maintain a high level of saturation. Air saturated pore space is 
considered to be the only significant pathway for oxygen diffusion into the tailings mass. The rate of oxygen ingress may therefore be less affected by moisture content above the shrinkage limit that intuition may suggest.

- The ARD generation rate was found to decrease linearly with increasing beach thickness.

- Field observations indicated that surface crust formation may play a significant role in reducing permeability of the tailings to water and gasses.

\section{CONCLUSIONS}

From the above data it can be concluded that for the Bulyanhulu paste tailings, deposition of thicker beaches with longer waiting periods between depositional events is preferable from a geochemical perspective. This is due to a lower fraction of sulphur oxidation for increasing beach thickness, despite longer drying times, relative to thin beaches.

The same relationship was not observed for geotechnical constraints, as an optimum deposition rate was found to occur at a $600 \mathrm{~mm}$ beach thickness, which was attributed to a non-linear decrease in moisture as a function of beach thickness and the amount of moisture transferred upwards from underlying tailings layers. Changes in boundary conditions may thus affect this conclusion, i.e. variation in moisture content and total thickness of underlying layers.

It thus follows that the optimum deposition interval is that in which a layer of tailings reaches the moisture content below which there is no further shrinkage, just in time to receive the next layer.

In the context of the Bulyanhulu tailings storage facility it would thus be better to concentrate deposition in one area until the full depth of a raise or geometric constraints for a beach had been reached before cycling to other deposition points.

\section{ACKNOWLEDGEMENTS}

The author would like to acknowledge the logistical and financial contribution made by the management and technical staff at Barrick and Bulyanhulu mine to make this project possible. The authors would also like to express their thanks to Mbike Jones and Akber Pabani who collected the data.

\section{REFERENCES}

Bethke, C.M. (1996) Geochemical Reaction Modelling. Oxford University Press. ISBN 0-19-509475-1. 
Das, B.M. (1995) Principles of Geotechnical Engineering. $3^{\text {rd }}$ ed. PWS Publishing Company.

Davis, G.B. and Ritchie, A.I.M. (1986) A model of oxidation in pyritic mine wastes, 1, Equations and approximate solution. Appl. Math. Modell, 10, pp. 314-322.

Evangelou, V.P. (1995) Pyrite oxidation and its control. CRC Press. ISBN 0-8493-4732-7.

Morin, K.A. and Hutt, N.M. (1997) Environmental geochemistry of minesite drainage. practical theory and case studies. MDAG Publishing. ISBN 0-9682039-0-6.

Perkins, E.H., Nesbitt, H.W., Gunter, W.D., St-Arnaud, L.C. and Mycroft, J.R. (1995) Critical review of geochemical processes and geochemical models adaptable for prediction of acidic drainage from waste rock. Mine Environmental Neutral Drainage (MEND) Program Prediction Committee. MEND Project 1.42.1

Price, W.A. (1997) Guidelines and recommended methods for the prediction of metal leaching and acid rock drainage at minesites in British Columbia. Reclamation Section, Energy and Minerals Division, Ministry of Employment and Investment, Bag 5000, Smithers, BC. V0J 2N0.

Theron, M., Addis, P., Wates, J. and Shuttleworth J. (2005) Buyanhulu Mine (Tanzania) Paste Tailings Facility: Relating the unsaturated properties of gold tailings to rate of rise. Paste 2005. April, Santiago, Chile.

Wates, J.A., Strayton, G. and de Swardt, G. (1999) Long term integrity of tailings deposits. Proceedings from Geotechnics for Developing Africa. ISSMFE Regional Conference. Durban, South Africa.

Wunderly, M.D., Blowes, D.W., Frind, E.O. and Ptacek, C.J. (1996) Sulfide mineral oxidation and subsequent reactive transport of oxidation products in mine tailings impoundments: A numerical model. Water Resources Research, Vol 32, No10, pp. 31733187. 